Swarthmore College

Works

1999

\title{
Who's Not Working And Why: Employment, Cognitive Skills, Wages, And The Changing U.S. Labor Market
}

Frederic L. Pryor

Swarthmore College, fpryor1@swarthmore.edu

D. L. Schaffer

Follow this and additional works at: https://works.swarthmore.edu/fac-economics

Part of the Economics Commons

Let us know how access to these works benefits you

\section{Recommended Citation}

Frederic L. Pryor and D. L. Schaffer. (1999). "Who's Not Working And Why: Employment, Cognitive Skills, Wages, And The Changing U.S. Labor Market". Who's Not Working And Why: Employment, Cognitive Skills, Wages, And The Changing U.S. Labor Market.

https://works.swarthmore.edu/fac-economics/86

This work is brought to you for free by Swarthmore College Libraries' Works. It has been accepted for inclusion in Economics Faculty Works by an authorized administrator of Works. For more information, please contact myworks@swarthmore.edu. 


\section{Final Observations}

In the previous eight chapters we present our explanation for the major trends in the U.S. labor market over the last quarter-century. In particular, we focus on explaining four critical and interrelated trends in employment and wages. Along the way, we cover considerable territory and, therefore, it is useful to provide a perspective by briefly restating our entire argument. We must then try to answer several broad and important questions: Will joblessness, particularly among prime-age males, continue to rise? Will other labor market trends of the past quarter-century continue into the future? And what measures are available to the government to ameliorate some of the adverse effects of the trends we document?

\section{A Summary of the Analysis}

The framework for our labor market analysis is a model of four distinct labor markets defined by occupation. The tier 4 labor market consists of the market for all the jobs in occupations with the highest levels of education intensity. The tier 1 labor market consists of the market for all the jobs in occupations with the lowest levels of education intensity. The tier 3 and tier 2 labor markets fall in between.

Within each labor market, we assume that supply and demand determine employment and wages, subject to a considerable degree of wage stickiness. This wage stickiness is generated by various "efficiency wage" type situations in which individual firms decide that the advantages of lowering wages (for instance, lower salary costs) are outweighed by the disadvantages (for instance, lower morale, higher turnover, more shirking).

In this type of framework, excess supply in the tier 4 labor market is not quickly eliminated by falling wages. Instead some people with the education and the aspiration to obtain a tier 4 job are unable to do so. As a result, they are forced to look for a job in a lower tier occupation. As they do so, this creates excess supply in the lower tier markets which is only partly eliminated 
by wage declines. At the end of the process, some potential workers are left jobless. In the long-run, perhaps, wages may decrease enough to absorb this excess supply, or labor demand may increase, or labor supply may decrease. However, in the short-run, some individuals are displaced completely from the labor market while others are displaced into labor market tiers lower than the one matching their educational levels and aspirations.

Table 9.1 summarizes the major strands of our empirical argument. Among men, employment rates have fallen over the past quarter-century, especially among those with less education. Employment rates for women have risen, but least among those with less education. Although the number of jobs requiring more education has risen considerably faster than the number with lower educational requirements, the number of educated workers has risen even faster. Moreover, women have filled a disproportionate number of these jobs. These two circumstances have initiated a chain reaction of job displacements. More specifically, university-educated women have replaced men with a similar education, but with lower cognitive abilities than others with the same education. Those displaced have taken jobs previously held by workers with less education who, in turn, have displaced those with even lower cognitive skills. Many of the least-educated workers have been knocked completely out of the labor force.

Although the number of jobs that can be fulfilled by those with just a highschool education or less is increasing faster than the number of prime-age workers with the corresponding educational credentials, real wages in these jobs have stagnated or fallen. In other words, excess demand for workers in the lower tier labor markets seems to result in a decrease in wages. This is due to the fact that the pool of workers competing for such jobs has been augmented by those with more than the requisite education who are displaced from jobs commensurate with their education, the same mechanism that has led to a rise in joblessness among the less-educated. In addition, the greater dispersion in education levels among those working in low-level jobs has increased wage inequality within most of these occupations.

Although the jobs that can be fulfilled only by those with a university education have increased more slowly than the number of prime-age workers with the requisite educational credentials, average real wages in these jobs have risen. In other words, a situation with excess supply of workers in the highest tier labor market seems to result in an increase in average wages. This is due to a technology - and institution - driven segregation of the tier 4 labor market into two sectors which we might call tiers 4-A and 4-B.

Tier 4-A consists of most professionals in the health care and legal service industries, as well as workers with particularly high cognitive skills in some of the other education-intensive occupations. Increased demand for health and 
Table 9.1: A Summary of the Major Arguments Made in This Book

Observable changes in the U.S. economy over the last quarter-century

1. Increased joblessness of poorly educated prime-age males (Chapter 1)

2. Downward occupational mobility, e.g., increased number of college graduates taking "high-school" jobs (Chapter 2)

3. Increased rate of return to a college education (Chapter 5)

4. Increased wage inequality throughout the labor market (Chapter 6 )

Exogenous causes of these changes

1. Causal factors of primary importance:

A. Increased labor force participation rate of women with at least a highschool diploma (Chapters 1, 4)

B. Skill-biased technological change: Increased demand for workers in tier 4 occupations who also have high cognitive skills (Chapter 5)

C. Increased average level of education of the population (Chapters 2, 3)

2. Causal factors of secondary importance:

A. Expansion of demand for professionals in health care and legal occupations (Chapter 6)

B. Increased winner-take-all wage setting in tier 4 occupations (Chapter 6)

C. Lower real minimum wage (not discussed in detail)

D. Decreased union participation and bargaining power (not discussed in detail)

E. Pool of high-school dropouts has increasingly lower average abilities as more able members obtain more education (not discussed in detail)

3. Causal factors of little importance

A. General technical change

i. Especially in low-skilled occupation (Chapters 3,7)

ii. As a cause of turbulence in the labor market (Chapter 7)

B. Changes in the structure of production and productivity (Chapter 7)

C. Increased imports, especially from developing nations (Chapter 7)

D. Increased immigration, especially with low levels of education (Chapter 7)

E. Increased geographical mismatch between jobs (in suburbs) and workers (in cities) (Chapter 7)

F. Subjective factors (Chapter 8)

legal services, plus the peculiar instituions of these sectors, have increased the demand for well-educated workers in these industries. In many other industries skill-biased tehcnical change has increased the demand for workers with high cognitive skills and a university degree faster than the supply. Average real wages in tier 4-A have increased considerably over the last quarter-century.

Tier 4-B consists of university graduates with average or below-average cognitive skills who are not in the health care or legal services industries. Given the large-scale entry of women with a university degree into the workforce, this group has seen their wages stagnate or decrease slightly. Wage stickiness prevents these wages from decreasing dramatically, but also it 
ensures that some of these workers are unable to obtain any job in the tier 4 labor market. These workers either opt for a lower-paying job in the tier 3 or tier 2 labor markets or they leave the labor force completely.

Average wages for all college graduates increase only because occupational tier 4-A has experienced such large wage increases. Median wages for all prime-age men with a university degree have actually decreased (see Table 5.1). This segregation of the tier 4 labor market into two sectors also helps to explain the relatively large increase in wage inequality across workers with a university degree.

While providing the evidence for these propositions, we also show that other explanations for the changing employment rates do not play a major role. More specifically, the falling employment rates of the less-educated cannot be tied in a major way to general technological change, increased turbulence in the labor market, the increasing importance of imports, rising numbers of immigrants, or increasing geographical mismatch between jobs and workers.

Two last questions remain: First, are the changes in the labor market that we have analyzed going to continue? The most pessimistic answers are offered by those economists who have raised the possibility of a new stagnation of employment and production in advanced capitalist societies. We need to explore, however, whether the causal forces influencing the labor market in the last quarter-century will remain as important. Second, if the current employment and wage trends continue, what general policy options are open to alleviate some of the major problems?

\section{Is Rising Joblessness Inevitable in the U.S.A.?}

The stagnation hypothesis - that advanced capitalist economies must inevitably experience long-term unemployment - is making a comeback in recent years. ${ }^{1}$ This time around, however, the justification of the stagnation hypothesis lies not just in a deficiency of aggregate demand or automation that displaces workers but in structural changes in the economy. For reasons outlined below, we remain unpersuaded by these claims. Nevertheless, it is important to look briefly at these arguments.

Economists have advanced many different reasons why unemployment or joblessness might occur. Stagnationists argue that some of these reasons are becoming more important over time. The traditional stagnation argument generally starts from demand side considerations: As our wants allegedly become satisfied with rising per capita income, aggregate demand will not rise as fast as our production potential, and the unemployment rate rises. Given the fact

1 An extreme form of the argument is by Rifkin (1995). 
that consumption is rising faster than income, this argument appears to have been abandoned. Thus, stagnationists have focused attention instead on certain supply side factors and policy considerations, particularly those related to the impact of increasing world economic integration ("globalization") and the effects of automation.

According to John Eatwell (1996-b), for instance, the post-Bretton Woods trading and payments system has been unable "to deal with international trading imbalances other than by deflation and growing unemployment in weaker countries - a deflationary impulse that has proved contagious." This is exacerbated by the deregulation of global markets and the huge increase in shortterm capital flows, driven especially by currency speculation. The economic consequences include wild currency rate fluctuations and much greater exchange rate risks to domestic producers and traders. Among other things such risks discourage investment, which in turn limits the growth of employment.

To reduce these risks, government policy-makers must place greater emphasis on the maintenance of market credibility, especially those associated with deflationary policies. In short, central banks have increasingly elevated financial stability over employment as policy priorities.

Alice Amsden (1996) raises other considerations associated with globalization. With the fall of barriers to international trade, the ratio of imports to total domestic production has been rising in most nations. As a result, governments are less capable of using fiscal policy to reduce unemployment because a larger share of any domestic fiscal stimulus leaks into the international economy, rather than raising employment at home. This is exacerbated by the convergence of technological capabilities throughout the world, signifying the loss of U.S. technological hegemony. Among other things this updating of Raymond Vernon's argument about the product cycle means that competing products are being produced in many different countries, so substitution of domestic by foreign products is easier.

She also argues that the increased global competition gives greater incentives for labor-saving process innovations. When the U.S. had technological dominance in the world, such increased productivity led to greater exports and domestic employment. In recent years, however, such downsizing measures are increasingly necessary merely to meet foreign competition and maintain sales in domestic markets, resulting in no additional employment.

Finally, the global technological convergence, abetted by multinational firms, means that the product cycle is shortened and production innovations in one country are rapidly copied in other countries. Such increased competition lowers the rate of return to innovation, which leads to less investment and lower employment increases. 


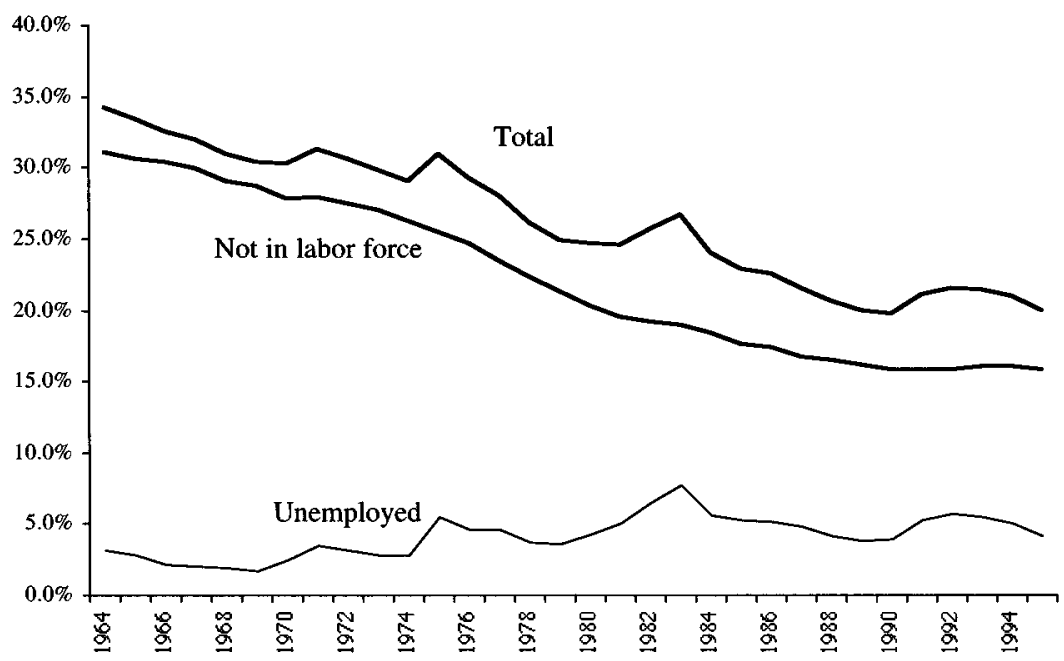

Chart 9.1: Joblessness among prime-age men and women

Although we do not wish to enter these arguments in detail, three general comments are in order. First, the endpoint of globalization is not in sight and U.S. integration into the world economy, at least as measured by the rising rate of imports to the GDP, shows no sign of abatement. Second, it seems indisputable that increasing globalization is placing increasing constraints on the efficacy of monetary and fiscal policy. This is occurring for the same reason that fiscal and monetary policy by state and local governments is seldom an effective way to reduce unemployment. ${ }^{2}$ Finally, some risks associated with increasing integration into the world economy, for instance, exchange rate fluctuations, can be insured against through the futures market and other institutions.

The key argument against the stagnationists is empirical. The data in Chart 9.1 show a declining rate of joblessness over the 31-year period from 1964 through 1995. Although the percentage of the unemployed prime-age workers has risen, the percentage of those who are totally out of the workforce has plummeted. This fall is primarily due to the entry of women into the labor

2 For fiscal policy we are speaking of employment effects other than on the first round. Clearly a government can put unemployed workers to work by borrowing and paying them to do something, but the second round effects for a highly open economy such as a city or a region are seldom very significant. 
force, which has more than offset the withdrawal of prime-age men. That is, overall labor market absorption has been high, even though the employment situation for particular subgroups such as less- educated prime-age males has deteriorated markedly. We might add that our investigations in Chapter 7 also show that not much of the change in the U.S. employment rate can be explained by the nation's increasing involvement in international trade.

To digress briefly from the path of our narrative, we looked fleetingly at the problem of how to measure the "tightness" of the labor market to explore certain facets of the stagnationist arguments. Throughout this book, we have been examining the rate of joblessness, and yet in most discussions the unemployment rate is generally considered the preferred measure of labor market problems. The issue is particularly acute for those trying to estimate the relation between tightness of the labor market and inflation (the Phillips curve). A typical equation relates price increases (for instance, of the GDP deflator) to some measure of price expectations (such as last year's increase in the GDP deflator), some measure of price increases coming from the outside world (such as the increase in crude material prices), and some measure of labor market tightness such as the unemployment rate for the economy as a whole.

This standard approach does not, however, explain the simultaneous decrease in unemployment and inflation that occurred in the mid 1990s. If we instead use the jobless rate among prime-age males as a measure of labor market tightness, the calculation yields a much better statistical fit. This is because the jobless rate decreased only slightly during the $1990 \mathrm{~s}$, so that according to this measure the labor market tightness did not markedly increase. ${ }^{3}$

\section{Will Employment and Wage Trends of the Last Quarter-Century Continue in the Future?}

This brief exploration of the stagnation hypothesis leads us to a more important question, namely whether the trends we have chronicled in the last 25 years are bound to continue. We approach this issue by asking a more tractable question: Does the period from 1970 through 1995 exhibit sufficiently unique features that they cannot be expected to recur in the future? Table 9.1 suggests that the three primary sources of these trends are the

3 More specifically, for the period 1987 through 1997 the coefficient of determination when using the unemployment rate measure is .7854 and is .8931 when using the jobless rate for prime- age males. For the period 1980 through 1997, the jobless rate still provides a superior fit, although the difference is much less. The coefficients of determination are respectively .9496 and .9599 . The data for this calculation come from the national income and product accounts, the producer price index of the Bureau of Labor Statistics, and our calculations 
increased labor force participation of women, a particular type of technological change, and the increased average level of education. We will briefly examine each of these.

\section{Increased Labor Force Participation of Women}

The increased labor force participation of women over the last quarter-century has led to a labor absorption problem: the large increases in labor demand have not kept up with the even larger increases in labor supply. Will this continue? To answer this it is useful to examine certain key indicators for the entire period from 1950 to the present to show that the problem of labor absorption during this period was particularly acute.

From the data presented in Table 9.2, we can draw two quick conclusions. First, the decade of the 1970 s featured the fastest growth in population of potential workers. This is, of course, the result of the baby-boom generation reaching the legal minimum age for employment, and indicates a serious problem of labor force absorption. The prime working-age population reached its peak growth in the decade of the 1980s. Second, the faster growth of the employed labor force indicates a rising labor force participation ratio. This, of course, is the result of the rapid influx of women into the labor force, and it exacerbates the labor-force-absorption problem.

In certain respects these conditions are not likely to be repeated in the foreseeable future. In the quarter-century from 1995 to 2020 , the U.S. Census Bureau (1996) projects that the population (middle series) from 16 through 64 will grow at average annual rates of 0.7 percent, an estimate that includes the "baby-boom echo." This, of course, is significantly lower than the average annual rate of 1.4 percent that this population grew between 1970 and 1995, fueled primarily by the post-World War II baby boom.

Furthermore, the rapid increase in the employment rate of women is unlikely to be repeated. As shown in Table 9-2, the growth of average employment rates of women in the prime working-ages began to decelerate in 1980-84, when it rose 7.3 percentage points over the previous five years. By the first half of the $1990 \mathrm{~s}$, the prime-age female employment rate increased only 2.4 percentage points over the previous five years.

Several counteracting factors can be mentioned. Women have increasingly more education which is associated with higher levels of labor force participation. Moreover, as long as the average wages of women are less than those of men, employers have an economic incentive to substitute female for male employees. These, however, do not seem strong enough to offset public opin- 
Table 9.2: Indicators of the Growth of Population, Labor, Capital, and Investment

Indicator

Average annual growth rates

Civilian non-institutional population,
Employed civilian labor force
Gross reproducible tangible wealth
Net reproducible tangible wealth

$1950-1960-1970-\quad 1980-1990-$

$\begin{array}{lllll}1960 & 1970 \quad 1980 & 1990 \quad 1995\end{array}$

$\begin{array}{lllll}0.8 \% & 1.5 \% & 2.0 \% & 1.1 \% & 0.9 \%\end{array}$

$\begin{array}{lllll}1.1 & 1.9 & 2.1 & 2.0 & 1.0\end{array}$

$\begin{array}{lllll}3.3 & 3.6 & 3.4 & 2.9 & 2.6\end{array}$

$\begin{array}{lllll}3.8 & 4.0 & 3.2 & 2.6 & 2.1\end{array}$

Annual averages

$1950-1960-\quad 1970-\quad 1980-1990$

$\begin{array}{lllll}1959 & 1969 & 1979 & 1989 & 1995\end{array}$

Ratio: total gross investment to GDP

$23.0 \% \quad 20.4 \% \quad 20.7 \% \quad 20.5 \% \quad 17.3 \%$

$\begin{array}{lllll}14.2 & 12.4 & 11.0 & 9.1 & 7.0\end{array}$

Share of total investment in government sector

$\begin{array}{rrrrr}28.9 & 25.6 & 17.6 & 17.3 & 18.9 \\ -0.6 & -3.0 & -1.3 & 8.3 & 6.8\end{array}$

Federal government deficit as a share of total $-0.8 \quad-1.9$

$9.6 \quad 16.2$

18.8

investment

$\begin{array}{lllll}1970- & 1975- & 1980 & 1985 & 1990- \\ 1974 & 1979 & 1984 & 1989 & 1994 \\ & & & & \\ 92.5 \% & 90.0 \% & 87.6 \% & 88.7 \% & 87.2 \% \\ 48.7 & 55.5 & 62.8 & 68.8 & 71.1\end{array}$

Employment rates: Prime-age males

Employment rates: Prime-age females

Notes: The gross capital stock and investment data include investment in both the private and public sectors.

Sources: The population and labor force data come from Council of Economic Advisors (annual, 1997), Tables B-32 to B-34. The wealth data come from: U.S. Department of Commerce, Bureau of Economic Analysis (monthly, 8/1994), p. 62, supplemented by data for 1994 supplied by the Bureau of Economic Analysis and our own estimates for 1995. The national accounts data come from Council of Economic Advisors (annual, 1997), Tables B-1, B-24, B-30, and B-34, supplemented by U.S. Department of Commerce, Bureau of Economic Analysis $(1992,1993)$, Tables 1-1, 3-2, and 5-1 plus our own estimate of depreciation of the government capital stock from 1950 through 1959. The data on employment of prime working-age workers come from the CPS.

ion results presented by Wattenberg (1991) indicating that the percentage of all women wanting to stay home has stopped falling. We believe it is likely that the percentage of women in the labor force will grow very slowly, or even level off in the next few years. 


\section{Skill-Biased Technical Change}

It is much more difficult to predict trends in technological change. We have identified that the two most important implications of recent technological change are a large increased demand for individual workers in higheducation occupations who also have high cognitive skills, plus a smaller increased demand for occupations in higher-education tiers. What type of technological change is behind this? We have no specialized data or knowledge in this area, but we do believe that much of the technological change that has affected labor demand can be attributed to the computer/electronic/communications/information systems revolution which began about a quartercentury ago.

Are the major changes caused by this revolution finished? Certainly there are incremental technological improvements occurring in these areas constantly. There also continue to be major changes every few years. The conversion of the command-line driven Internet into the World Wide Web (WWW), filled with millions of graphically intense "home pages" is perhaps the most recent example. In just three or four years, the WWW has dramatically changed the way that many economic transactions are handled, both within and between firms. Although it is hard to envision what the next big change will be, we are unlikely to see an end to such changes in the near future.

One constraining factor on technological growth deserves mention. In so far as new technology is embodied in new capital investment, it is necessary to consider capital accumulation. Table 9.2 shows that over the last quarter-century, capital was rising at a faster rate than labor, so that the capital/labor ratio was increasing. Nevertheless, the rate of increase of this ratio was much slower than in the first two decades of the post-World War II era. In recent years, the growth of the capital stock has declined as the ratio of investment to GDP has fallen. Although part of this was due to a fall in the share of investment carried out by various levels of government, the table shows that a major share was due to a fall in domestic savings. Indeed, the growth of the capital stock would have been even slower if foreigners had not increased their assets in the United States. If the savings rate continues to fall, the importance of the skill-biased technical change may lessen, other factors remaining the same.

\section{Rising Average Education}

Finally, what can be said about trends in average levels of education? In Chart 2.1 in Chapter 2 we present some relevant evidence. The fraction of the population completing at least some schooling beyond the high-school 
diploma has increased over the entire quarter-century. However, the rate of increase has slowed in recent years.

As the costs of most types of post-secondary education (including public) continue to grow much faster than average earnings, this deceleration may continue. On the other hand, our analysis throughout this book strongly supports the notion that obtaining a college degree will increase a person's expected lifetime income considerably more now than 25 years ago. This increases the incentive to acquire more education. It is likely, though, that the budget constraint issue will dominate for most of the population, at least barring massive new governmental subsidies to post-secondary education. This, in turn, will lead to a continued slowdown in the increase in average education, and perhaps a leveling-off of average years of education in the near future.

\section{Summary}

So how do we pull these predictions together? The shards of evidence presented above suggest that the displacement of men by women will be less strong in the future as the percentage of women in the labor force levels off. As a result, the impact of their disproportionate employment in jobs requiring more education will not be as great in the coming years as in the period from 1970 through 1995. Also, as the increase in the average level of education slows down, the downward occupational mobility generated by this will also level off. These considerations lead us to give even less credence to the pessimistic employment predictions of the stagnationists, even while we remain gloomy about trends in the distribution of wages.

The one highly unpredictable element is technological change. If it continues in its current direction, the demand for workers with both high education and high cognitive skills will continue to grow, as will wage inequality. If technological change, which is difficult to predict, diverges from its current trend, anything is possible.

\section{Some General Policy Implications}

This is not a book on labor market policies. Nevertheless, our arguments have some important implications, mostly negative, about the likely success of a wide range of public policies aimed at reducing the joblessness of less-educated prime-age workers and/or decreasing wage inequality. In this section we briefly describe the likely impact on joblessness, the wage level, and wage inequality of a number of widely discussed policies. For the sake of expositional clarity, we divide these polices into groups according to their 
focus on workers in low-wage or high-wage jobs (or all jobs) and to their direct impact on the supply or the demand side of the labor market, or on institutions involving both supply and demand.

\section{Policies Targeted at Low-Wage Workers and the Jobless}

It is useful to distinguish policies focusing on the supply and demand sides of the labor market with those dealing with overall market functioning.

Supply-side policies: Policies concerned with low-wage jobs and the supply side of the labor market usually focus on increasing human capital or establishing greater incentives for people to choose to work. The human capital policies, in turn, can target persons either before or after they first enter the workforce.

Several programs under discussion focus on improving the human capital of U.S. workers before they enter the workforce, either by increasing their years of formal schooling or by improving the content of their education. For instance, at the primary and secondary levels of education these include proposals to restructure the educational system by using vouchers, or the Murnane-Levy (1997) proposals to increase the effectiveness of education by teaching the "new basic skills." In 1997, at the university level, these proposed policies include plans by both the President and the Congress to give certain tax incentives for university study. The biggest weakness of such programs is the difficulty in improving the quality of education, especially in low-income urban neighborhoods, without improving many other characteristics of life there.

The alternative approach is to target human capital programs at jobless workers who are no longer in school. Unfortunately, the benefit/cost ratios of many such programs designed to improve the education and/or skills of lesseducated workers have been low. Indeed, some economists have argued that such a focus on low-skilled workers is not the most effective way of spending scarce educational resources (Heckman, Roselius, and Smith, 1994). Although the Job Training Partnership Act (JTPA) led to modest wage gains for adult women that were higher than the costs of the program, for adult men and for youth, the program did not seem to have any significant impact on the income of the participants (Orr et al., 1995). Economists have also studied the benefits and costs of other job training programs, but their economic payoffs seem modest at best. ${ }^{4}$

This category of labor supply policies also includes proposals to cut back on unemployment insurance benefits, welfare payments, or Medicaid to increase incentives to work (actually, to decrease disincentives to work). These

4 Recent studies of the benefit/costs of job training programs include those of : Friedlander and Burtless (1994); Grubb (1996), Heckman, Lochner, Smith and Taber (1997), and Kodrzycki (1997). 
are, of course, harsher policies than those enhancing human capital. Discussion of such approaches usually hinge on the question about whether joblessness is voluntary or involuntary.

Policies aimed at changing work incentives also include raising the real value of the minimum wage. This is just a positive incentive version of reducing unemployment insurance benefits, welfare payments, or Medicaid. As such, it also creates an incentive for low-wage workers to choose to work, while also potentially increasing their economic well-being. Of course, the welfare increase only occurs if they can acquire a job at the new higher minimum wage. Unfortunately, an increased minimum wage may cause a reduction in the quantity of labor demanded.

From our viewpoint in this book, the major problem with all of these labor supply policies is that they may not lead to any net increase in employment. Instead, such policies may just lead to new types of displacement as those who are lucky enough to benefit from a human capital enhancing program or unlucky enough to be cut off from a welfare-type program, will be in a better position, and try harder, to take a job away from another relatively low-wage worker. If this happens, net employment will be unchanged. The wage rate paid may increase because the new worker is more productive than the old worker, or decrease, because the number of persons competing for the job is greater. Thus, wage inequality can either narrow or widen.

This problem of displacement is a serious one. The employment equations (Table 2.4) suggest that those obtaining additional education will increase their probability of employment. For instance, a GED does increase employment rates. We need to take into account, however, the fallacy of composition: what is true for a single individual may not necessary be true for an entire group which, in this case, is the entire cohort of those with the same education. For instance, if education among the less-educated is upgraded, without changing the number of jobs available, only the educational mix of the unemployed will change. In addition, those who still have not obtained higher educational credentials may end up with highter rates of joblessness.

We do not mean to imply that such education policies should be abandoned, because such policies achieve other social goals. In particular, decreasing the number of less-educated workers and increasing the number of more-educated workers can have one useful long-run outcome. It would result in a reduction in the relative price (or wage) of more-educated workers and therefore encourage producers to adopt more advanced methods to take advantage of the lower cost of such skilled workers. This, in turn, would help in the long-run to maintain the nation's position as a technological leader. But such policies would not, in and of themselves, create new jobs in the short-term.

Demand-side policies: Policies targeting less-educated, low-wage workers and the jobless from the demand side include wage or employment subsidies 
that reduce the hourly costs to employers of hiring less-educated workers. These might lead to an increase in the employment of the least-educated, and, although a small amount of displacement might occur, it would certainly be less than with policies enhancing human capital. This would not necessarily lead to a change in wage inequality, but it would lead to a decrease in income inequality as more of the less-educated are employed.

On the negative side, such subsidized workers could be stigmatized, increasing the reluctance of employers to hire them. Results of experiments of certain wage-subsidy programs have been mixed, although not all parameters of such policies have been thoroughly explored. Recently, Edmund Phelps (1997) has made a strong case for employment subsidies, arguing that besides the obvious direct benefits to recipients, the indirect positive benefits greatly outweigh the indirect negative impacts.

Market-functioning policies: Market functioning policies facilitate the matching of less-educated workers to jobs by either direct or indirect methods. The former include programs that are specifically aimed at helping individual low-income persons find employment. In this regard it is important to note that programs to help workers find jobs have had a higher payoff to the individuals involved than the job training programs. Unfortunately, Uchitell (1997) shows that helping welfare recipients obtain jobs often means that the working poor who hold these jobs find themselves unemployed. Thus, federal mandates for job creation for one group of the less-educated workers can take away employment from another group - the displacement problem again.

A similar conclusion would apply to any attempts to reduce the amount of "credentialism" in the hiring process. For instance, some have argued that weakening anti-discrimination laws would make employers more willing to test workers for both hard and soft skills without having to worry as much about lawsuits claiming that the tests have little to do with the direct requirements of particular jobs. Such a measure might alter the mix of workers that a typical firm hires. Those with the least education would certainly have a better chance of being offered a job if "credentials" were not the primary hiring determinant. Nevertheless, such a change would not necessarily lead to an increase in the total number of jobs available.

Additional indirect programs matching less-educated workers to positions requiring few skills include those requiring employers to list all job openings at a central employment registry. By consolidating the dissemination of information about job openings, both information costs to job seekers and unfilled job-openings would be reduced. 5 Improved public transportation would also help central city dwellers reach jobs in the suburbs.

5 Of course, it is possible that greater employment of the less-educated could come at the 


\section{Policies Targeted at Medium- or High-Wage Workers}

The policies discussed so far are all aimed at the jobless and those in low-wage jobs. Yet our analysis suggests that the cause of their employment problems lie in a different part of the labor market. Are there any policies which deal more directly with the source of the problem? We again divide these policies according to the same criteria as used above.

Supply-side policies: One intriguing supply-side policy has received considerable discussion in Europe, namely work sharing and/or work spreading. For instance, in some of the middle and high-wage occupations, each worker could work fewer hours per week (at approximately the same hourly wage rate) and more total workers could be hired. Within our model, this would lead to less downward occupational mobility and would alleviate some of the excess labor supply in the low-wage jobs. This would decrease joblessness among the less-educated and also raise wages. It would probably result in a decrease in wage inequality as the lowest wages move a little closer to the middle of the overall wage distribution.

Such policies would, of course, have an impact on average weekly working hours which slowly declined in the U.S. until 1990, when they began to level off (Bureau of the Census, annual, 1995, Table 666). Certainly, measures could be taken to encourage enterprises to begin cutting back further on the hours worked by existing workers, and to begin hiring new workers as substitutes.

These policies have two major difficulties. Unfortunately, many kinds of work require high fixed costs for new workers - recruiting, training, benefits, and logistics - so that this solution is often costly. Moreover, policies leading to the reduction of work hours means lower weekly earnings and many families may not willingly accept such a situation.

An alternative supply-side approach would be to increase the cognitive skills of many of the low- and middle-level college graduates. They could then take advantage of the excess demand for these skills, receive a high wage, reduce downward occupational mobility, and alleviate some of the excess labor supply in the low-wage occupations. Unfortunately, there are no widelyaccepted ideas as to how to accomplish this proposal.

Demand-side polices: Demand-side policies targeting medium- and highwage jobs have received little discussion and it is difficult to think of any that would be politically feasible. Given this consideration, it is ironic that our analysis suggests that the most direct way to remedy the increased joblessness

expense of more-educated workers, who are now holding these jobs and who could be more readily replaced. In this case, such a program might also lead to a reduction in wages in these low-skill jobs because of the increased competition. Of course, replacement might not occur if employers preferred to hire workers with more educational credentials than those necessary for the job. 
and lower wages among less-educated persons is to increase the demand for college graduates with average or below-average cognitive skills. The most obvious way to do this is through wage or employment subsidies to firms that hire such college graduates. This would keep average and below-average college graduates from competing for jobs in tier 3 and tier 2 occupations and thus prevent the displacement mechanism from occurring. Of course this would require a method for distinguishing which types of jobs and/or college graduates would be eligible for the subsidy - a very difficult task. However, the biggest obstacle to this type of program would be the perception that the people with the most education - and therefore the best chance of economic success are receiving a subsidy which less-educated persons are not.

A slightly more realistic demand-side policy - which would help reduce wage inequality but not joblessness - would be salary caps. In the U.S., the only well-known examples of such salary caps are for various types of government workers but, of course, they could also be imposed on private sector firms in the same way as the minimum wage mandate. Much recent public discussion has focused on the possibility of imposing salary caps on CEOs - perhaps defined as some fixed multiple of the average non-executive wage within their company. There have been some grass-root attempts by workers and shareholders to get CEOs to accept a "voluntary" salary cap as evidence of commitment to everyone involved with the firm. It should not be surprising, however, that no prominent CEOs have accepted such an agreement.

Market-functioning policies: Market functioning policies focusing on the labor market for medium- and high-wage jobs in order to decrease joblessness or reduce wage inequality have received little public attention. While it is doubtful that any feasible policy could reduce joblessness at this level, wage inequality can be accomplished with progressive income, earnings, or consumption taxes. In the U.S. we currently have a progressive income tax, although it is less progressive today than at any time since the 1950s. This is the most direct type of policy to reduce wage inequality, but it does nothing to improve the problems of joblessness and low-wages among less-educated workers.

\section{Policies Targeted at the Entire Labor Force}

A more direct solution to the problems of joblessness and wage inequality lies with economy-wide programs to accelerate the job creation process, regardless of educational credentials required in these new job openings. Since the absorption problem of less-educated workers will be less acute in the coming quarter-century than in the last 25 years, problems of job creation by public policy are more tractable than in the recent past. We must note, of course, that job creation in the U.S. over the period under examination has 
been higher than almost any industrialized country in the world, an achievement driven partly by a faster growth of the labor force. But U.S. labor force participation rates have also been among the highest in the OECD. 6 Nevertheless, the rising jobless rates among less-educated males in the U.S. suggests that even more should be done.

Such job creation policies are easier to prescribe on a general level than to design the particulars. In the short-run, such policies could involve some combination of expansionary fiscal and monetary policies. In the long-run, such policies could focus on increasing savings and investment so that the capital stock grows. The latter would typically lead to some increase in the demand for labor (capital widening). In some cases an increasing capital stock could just increase the productivity of existing workers (capital deepening) and lead to higher wages but no increase in employment.

A major difficulty with such policies is that the short-run requirements often conflict with the long-run requirements, and the long-run requirements are difficult to implement. If strongly expansionary fiscal policies are combined with moderately restrictive monetary polices, as was done through much of the 1980s, this leads to short-term job creation plus high interest rates. However, the high interest rates discourage investment which is necessary for the long-run goal of increasing the capital stock. Thus, an alternative short-run strategy might involve strongly expansionary monetary policy with mildly contractionary fiscal policy. With this combination, the private savings formerly used to finance the government deficit would be diverted to the private sector. Interest rates would fall initially, which would encourage more investment. The obvious problem is that such policies, unless carefully administered, might unleash inflationary forces which, in turn, would eventually result in increased interest rates and reduced investment.

What if we ignore short-run job creation and focus strictly on long-run results? Unfortunately, we are not sure how to increase savings and investment in the long-run. Considerable debate currently centers around the issue of whether the savings incentives offered by the U.S. government (such as IRAs or 401(k) plans) have actually led to an increase in savings. We believe that they probably haven't been very effective, as evidenced by the general decline in the personal savings rate in the last several decades. The appropriate data on the issue, however, are fiendishly difficult to interpret. ${ }^{7}$

6 OECD (1996), p 196. Of the 24 nations with labor force participation data from 1973 through 1995, the increase in the U.S. was fourth highest. Only Iceland, Netherlands, and New Zealand were higher.

7 A useful summary of the current state of the debate is found in the exchange between Hubbard and Skinner (1996), Poterba, Venti, and Wise (1996), and Engen, Gale, and Scholz (1996). 
Although additional saving might result in lower interest rates, a related question is whether this would lead, in turn, to more domestic investment, instead of flowing abroad. Some such as Bayoumi (1990) argue that although governmental policy may influence savings and investment at a single point in time, savings and investment are correlated over time primarily because of disturbances to the economy as a whole. This means that attempts to increase domestic investment financed by domestic savings have little long-term impact

Of course, it is also possible that direct job creation policies, for instance, investment incentive programs such as reduction of the capital gains tax on new investment or, for that matter, tax incentives tied directly to job creation, might be more effective than saving incentives. But enormous controversy exists over the cost effectiveness of such measures that have been tried in the past. Still on the micro-level, a restructuring of capital markets to increase the quality of information available to potential lenders might reduce their lending risks and increase aggregate investment. Unfortunately, specification of the most effective investment incentive program to encourage job creation would take us light years away from the major theme of this book and, therefore, must be left for others.

One simple policy truth must be stressed. Simply increasing the demand for workers by the creation of new jobs would not be enough. Such policies would also have to be combined with other programs to match workers with jobs. In addition, effective methods of determining the actual skills of individual workers so that employers would not need to rely on formal educational credentials alone, would have to be combined with changes in labor market institutions so that better information about available jobs is available.

\section{Final Words}

Our analysis also has one last important policy message. Until the problems of obtaining more employment for less-educated men and reducing wage inequality are viewed in terms of the entire labor market, the key parameters for policy success remain hidden. Of course, the unprecedented boom in the last decade of the century did lead to a fall in unemployment and narrowing of wage differentials in the late 1990s. Nevertheless, by the beginning of the new millennium the jobless rate was still at a very high level and the level of wage inequality was much higher than a quarter of a century before. Although macro-economic success can reduce the magnitude of these problems, the basic labor market difficulties still remain.

These problems must be viewed broadly in order to judge the real impact of programs designed to help a particular segment of the labor force. It is our hope that this study provides such a perspective to the joblessness and lowwage problems that have had a devastating effect on so many lives. 